\title{
Temperature dependence of methanol and the tensile strength of insulation paper: kinetics of the changes of mechanical properties during ageing
}

\author{
Oscar H. Arroyo • Jocelyn Jalbert • Issouf Fofana $・$ Mohamed Ryadi
}

Received: 9 September 2016/ Accepted: 4 November 2016/Published online: 10 November 2016

(C) The Author(s) 2016. This article is published with open access at Springerlink.com

\begin{abstract}
This paper reports the temperature-dependence of methanol generation and the tensile index under ageing conditions for two paper/oil systems: one consisting of a standard wood Kraft paper and the other of a thermally-upgraded Kraft paper (TUK). A linear correlation between methanol and the tensile index for these paper/oil systems was observed in a previous study at $170{ }^{\circ} \mathrm{C}$. In the current study, the correlation was extended to a large range of temperatures $\left(150-190^{\circ} \mathrm{C}\right)$. The experimental data were fitted with a modified Calvini's kinetic model, while the Arrhenius equation was used to model the kinetic of changes of the paper's mechanical properties during ageing. Good agreement with the temperature (lnk vs. $1 / T$ ) was observed for the rate constants of the chainend group production, methanol formation, and the
\end{abstract}

O. H. Arroyo $(\bowtie) \cdot I$. Fofana

Research Chair on the Aging of Power Network Infrastructure (ViAHT), Université du Québec à Chicoutimi (UQAC), 555 boulevard de l'Université, Chicoutimi, QC G7H 2B1, Canada

e-mail: arroyo.oscar@ireq.ca

J. Jalbert

Institut de recherche d'Hydro-Québec (IREQ), 1800

boulevard Lionel-Boulet, Varennes, QC J3X 1S1, Canada

M. Ryadi

Themis-Groupe Transformateur \& Alternateur, Électricité de France, 7 boulevard Gaspard Monge, 91120 Palaiseau, France decrease of mechanical properties. The Arrhenius equation applied to this data grouping showed activation energy of $130 \pm 29 \mathrm{~kJ} / \mathrm{mol}$ for the decrease in mechanical strength of the standard Kraft paper, while the value was $118 \pm 55 \mathrm{~kJ} / \mathrm{mol}$ for the TUK paper. These values are of the same order of magnitude as those obtained in this study and in the literature for the depolymerization of cellulose and the generation of methanol that was reported. This confirmed the close relationship between cellulose depolymerization, methanol generation and the reduction of the paper's mechanical strength during ageing, dominated by the acid hydrolysis mechanism. The results, which can be seen as a benchmark and pave the way to further research, provide an opportunity for applying the proposed correlations to estimate the insulation condition in operating transformers.

Keywords Methanol - Kinetics · Temperature dependence $\cdot$ Mechanical properties $\cdot$ Arrhenius equation - Power transformers - Degree of polymerization $\cdot$ Cellulose degradation

\section{Introduction}

Power transformers are among the core components of any electrical power systems. The insulation system of these major assets is formed by the insulating fluid/paper complex. An assessment of their condition 
involves monitoring both parts of the insulation system. Dissolved gas analysis (DGA) of transformer oils combined with other techniques such as the measurement of acidity, dielectric properties, moisture content, etc., are standard tools for monitoring their condition. It is possible to directly access the insulating fluid for sampling during reclamation or even during retrofilling. Determining the condition of the solid insulation requires opening the transformer for sampling. This is not possible for an operating unit. For this reason, techniques were developed to indirectly monitor the ageing and condition of the insulation paper, and hence the condition of power transformers. Determining an oil-soluble by-product of cellulose degradation, also known as a chemical marker, is therefore essential for the electrical industry. In the first and second generation of chemical markers of cellulose ageing, carbon oxides and 2-furfuraldehyde (2-FAL) dissolved in oil were used to estimate the level of degradation of cellulose-based paper impregnated in mineral oil. However, it was reported that the presence of carbon oxides might not only be specific to paper degradation but also to ageing of the oil. Additionally, 2-FAL sensibility worsens when thermally-upgraded Kraft papers (TUK) are involved (Yamagata et al. 2008). As third generation of chemical markers, methanol has been proven to be a good indicator for monitoring the different ageing stages of standard Kraft and TUK papers (Jalbert et al. 2007), while the presence of ethanol could be related to a thermal fault or hot spot within the solid insulation (Rodriguez-Celis et al. 2015). Under normal ageing conditions, the life of a power transformer is usually related to the loss of the mechanical properties of the paper in the windings (Wang et al. 2002).

In previous studies, it was shown that the acid hydrolysis mechanism drives the ageing of the cellulosic paper impregnated in oil for the range of studied temperatures, i.e. $\quad 60-210{ }^{\circ} \mathrm{C}$ (Gilbert et al. 2009, 2010; Jalbert et al. 2015). This finding allows accelerated ageing tests to be used at high temperatures to study ageing under normal transformer temperatures, such as the loss of the mechanical properties of the paper and its correlation with the methanol chemical marker. A linear relationship between methanol and the paper tensile index has been established during ageing studies. The first relationship was established using ageing cells equipped with a breathing system at $140{ }^{\circ} \mathrm{C}$, and the second using sealed ageing cells at $170{ }^{\circ} \mathrm{C}$ (Arroyo et al. 2014, 2015). This correlation is important because it allows the current state of the paper to be monitored using a chemical marker and has the potential to become a tool for power transformer assessment.

The authors would like to determine whether there is a linear correlation between methanol and the tensile index for a larger range of temperatures, i.e. $150-190{ }^{\circ} \mathrm{C}$, by accelerated tests using sealed ageing cells. The influence of temperature on the correlation is also discussed in this paper.

\section{Experimental design and procedures}

Materials-Inhibited iso-paraffin synthesized insulating fluid (Luminol TR-I (Luminol) by Petro Canada), two types of transformer insulating papers [standard wood Kraft paper (Munksjö) and thermally-upgraded Kraft paper (Rotherm)], and sealed ageing cells made of stainless steel for simulating a hermetic transformer were used in this study. For additional details about materials and equipment, please refer to our previous study (Arroyo et al. 2015).

The mass distribution of the materials for each ageing cell was $1.85 \mathrm{~g}$ of standard Kraft or $2.70 \mathrm{~g}$ of TUK, $55 \mathrm{~g}$ of copper, and $225 \mathrm{~g}$ of Luminol at $170{ }^{\circ} \mathrm{C}$. The $216 \mathrm{~g}$ mass of Luminol was optimized for oil expansion at $190{ }^{\circ} \mathrm{C}$ and maintained for the studies at $150{ }^{\circ} \mathrm{C}$.

Accelerated ageing conditions-Paper samples placed in copper holders were dried in the antechamber of a glove box at $40{ }^{\circ} \mathrm{C}$ for $48 \mathrm{~h}$ under a vacuum atmosphere. The paper samples where then moved from the antechamber to a double glove box at $0.9 \%$ relative humidity for at least one week for conditioning. A glass bottle containing Luminol oil was also conditioned under constant agitation at atmospheric pressure in the same glove box for at least $24 \mathrm{~h}$. When both materials reached the required equilibrium, the stainless steel ageing cells were introduced inside the glove box and the oil and paper were added to each cell. The ageing cells at air atmosphere were closed inside the glove box to avoid the absorption of external sources of humidity.

The stainless steel ageing cells were placed inside air-forced ovens (Salvis lab, type TC-100S) at temperatures of $150^{\circ}, 170^{\circ}$ and $190^{\circ} \mathrm{C}$. These relatively 
high temperatures were selected because they cause a much faster degradation in the paper. The cells were removed for analysis at different ageing times. They were then cooled and maintained at $17{ }^{\circ} \mathrm{C}$ for $24 \mathrm{~h}$. Oil aliquots were extracted for different analyses. Once opened, the cells were not returned to the oven. The paper samples were de-oiled with hexane and then conditioned under a laboratory hood at room temperature for at least $48 \mathrm{~h}$. These de-oiled paper samples were used to measure the tensile index and the degree of polymerization $\left(\mathrm{DP}_{\mathrm{v}}\right)$.

The test period was generally sufficient to reach values under the LODP (levelling-off degree of polymerization) of the papers. The LODP corresponds to the average length of the crystalline region of the cellulose.

Analysis techniques-The alcohols, methanol and ethanol dissolved in Luminol oil were analyzed using headspace gas chromatography with mass spectrometry detection. A detailed description of this method can be found in the literature (Jalbert et al. 2012). The 2-furfuraldehyde compound (2-FAL) in Luminol was analyzed using high-performance liquid chromatography (Agilent, 1100 series HPLC) based on a method shown elsewhere (Lessard et al. 1995) and ASTM Standard D5837. The water content and acidity in Luminol were analyzed by coulometric Karl Fischer titration based on ASTM D1533 and by titration according to ASTM D974.

ASTM Standard D828 was used to assess the tensile strength of paper and pressboard at a constant elongation rate. The tensile index (Tidx) is expressed as the tensile strength (tensile force per width of paper) divided by the grammage (mass per square metre of paper) of the samples. Ten paper specimens $25.4 \mathrm{~mm}$ wide and $130 \mathrm{~mm}$ long were measured for each ageing point. The tensile machine (Testing Machine Inc. Series 84-76) had an initial grip separation of $50 \mathrm{~mm}$ and a rate of grip separation of $7 \mathrm{~mm} / \mathrm{min}$.

The degree of polymerization of the paper samples was calculated using the average intrinsic viscosity value based on ASTM D4243. Two measurements were performed per studied sample to obtain an average value.

\section{Results and discussion}

The determination of ethanol, 2-furfuraldehyde (2FAL), water and acidity in the Luminol oil was performed. However, these results are not reported in this paper. The concentration of ethanol increases linearly with the duration of ageing and temperature, regardless of the type of paper or grammage. For the standard Kraft paper, the concentration of 2-FAL in oil is found to increase very slowly at the beginning of depolymerization; once the $\mathrm{DP}_{\mathrm{v}}$ decreases below 400, its concentration increases exponentially. For the TUK paper, the content of 2-furfuraldehyde in oil was always lower than the detection limit of the analytical method by liquid chromatography. The content of water and total acidity in oil increased with ageing duration and temperature.

Figure 1 shows the decrease of the degree of polymerization of cellulose versus ageing duration for the different ageing temperatures, for standard Kraft and TUK papers. The same behaviour is observed for all the temperatures and type of papers: an initial fast depolymerization, followed by a slower decrease during the rest of the ageing. This trend suggests the same type of degradation mechanism in the paper, regardless of temperature or type of paper, but shows different depolymerization rates and different time frames.

The influence of temperature over the depolymerization of the cellulose chains is direct but not linear, and appears to be exponential. The results also support the fact that the use of high temperature for accelerated ageing is acceptable if the LODP is reached. This is because the high temperature accelerates the transition between the different stages of ageing without missing any ageing steps. In all cases, the ageing of cellulose in standard Kraft and TUK paper has the same ageing steps, with the LODP level as endpoint. The difference is the rate at which the endpoint that is governed by ageing temperature is reached.

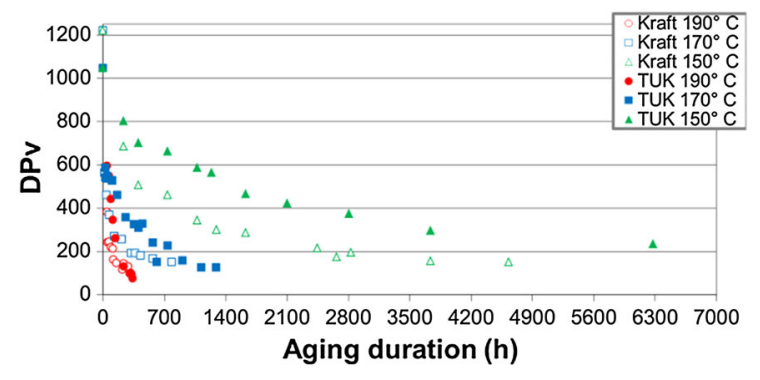

Fig. 1 Degree of polymerization during ageing of Kraft and TUK papers in Luminol at different temperatures 
For all the studied temperatures, the TUK paper samples show slower depolymerization compared with the standard Kraft paper. The presence of added nitrogenous organic substances in TUK papers produces a local partial neutralization of acids, mainly low-molecular-weight acids found in the paper surface. The nitrogenous bases also consume water. These actions slow down the effect of the acid hydrolysis on the cellulose chains. For the TUK paper at 170 and $190{ }^{\circ} \mathrm{C}$, the protection of the added nitrogen is effective but only for a short period of time, possibly due to the higher acidity generated at higher temperatures or because the nitrogen compounds become unstable at these temperatures.

Figure 2 shows the concentration of methanol in Luminol versus time for the different ageing temperatures for standard Kraft and TUK papers. In order to compare the results, the concentration of methanol was normalized by the grammage of the papers. The difference between the content of methanol in standard Kraft paper and TUK could be explained by the partition phenomenon (Jalbert et al. 2013). The partition effect explains the distribution of the molecules of methanol between the paper and the oil; this distribution varies when the conditions such as temperature, water content, type of paper, equilibrium time, etc. change. According to the partition effect, TUK papers release more methanol in Luminol than standard Kraft paper at the same level of cellulose degradation.

The results show two parts in each curve: the first is a linear generation of methanol with time, while in the second part of the curve, the concentration of methanol reaches a plateau level for the rest of the ageing. This behaviour can be explained as an initial easier access by the acid hydrolysis mechanism to the amorphous structures of cellulose. At a certain ageing

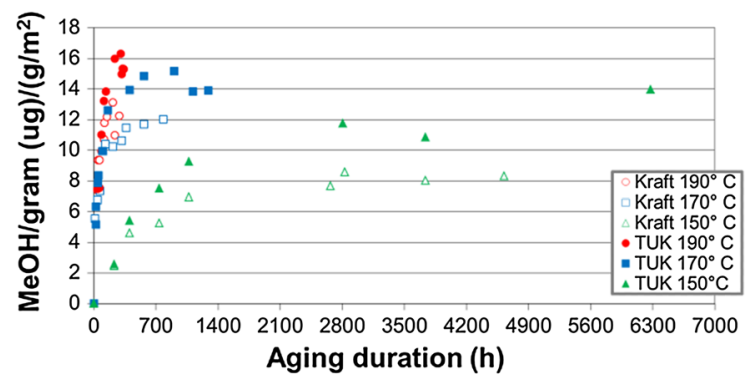

Fig. 2 Concentration of methanol in Luminol normalized by grammage for Kraft and TUK papers at different temperatures point, the production of methanol is almost constant, the amount of amorphous structures decrease, and the remaining crystalline structures are more stable, with the result that there is less production of methanol.

The temperature has a direct influence on methanol formation. At higher temperatures, there is a higher methanol generation rate. This indicates that at a higher temperature, the degradation in the sample is extended and more glycosidic bonds are broken to produce more methanol.

The concentrations of methanol at 170 and $190{ }^{\circ} \mathrm{C}$ are more similar in value than the concentrations at 150 and $170{ }^{\circ} \mathrm{C}$. This is due to the direct and exponential effect of ageing temperature over the generation of methanol. This similar effect of temperature over cellulose depolymerization was observed.

Figure 3 shows the correlation between the tensile index of the samples and the $\mathrm{DP}_{\mathrm{v}}$ values. This correlation can be seen as a master curve independent of the type of paper or applied ageing temperature. The curve describes the steps of cellulose ageing and the convergence towards the same endpoint. The temperature controls the degradation kinetics. However, the cellulose papers follow the same ageing steps and reaches the same endpoint at any temperature. The ageing endpoint, i.e. the agglomeration of points formed at the end of curve, should be considered as the limit or end of service for the paper. The endpoint has a $\mathrm{DP}_{\mathrm{v}}$ of around 150, a value near the LODP where the tensile index value is approximately $10-20 \%$ of the initial value. At this point, the paper has lost almost all its mechanical strength and has become very rigid and fragile.

The curve relates two paper properties at different structural levels. The tensile index is a macro level measurement of paper as material and the $\operatorname{DP}_{\mathrm{v}}$ is a

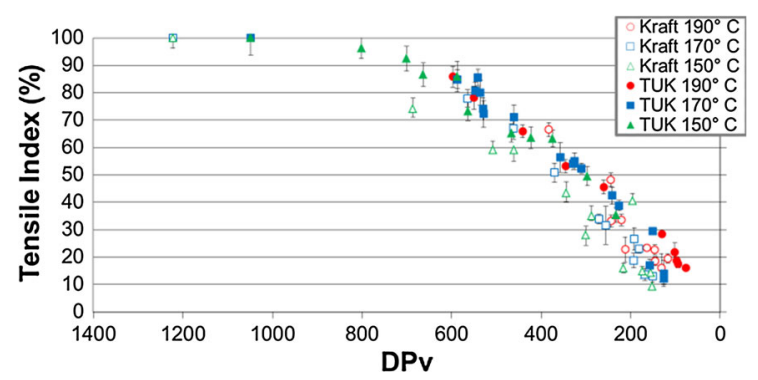

Fig. 3 Tensile index of paper samples versus degree of polymerization 
molecular level measurement of the cellulose chains length.

The relationship between the tensile index and the $\mathrm{DP}_{\mathrm{v}}$ can be separated in two sections. In the first section, the $\mathrm{DP}_{\mathrm{v}}$ presents a fast decrease where the acid produced by the hydrolysis mechanism easily affects the amorphous cellulose structure, from the initial $\mathrm{DP}_{\mathrm{v}}$ to a $\mathrm{DP}_{\mathrm{v}}$ of about 700 . However, the tensile index decreases slowly for this $\mathrm{DP}_{\mathrm{v}}$ range. In this range, the paper strength directly depends on the depolymerization of the cellulose as well as on factors such as interfibre bond strength among the cellulose fibres, individual fibre strength, and finally by the hierarchical structure of the paper (Kortschot 1997).

In the second section of the curve, the $\mathrm{DP}_{\mathrm{v}}$ and tensile index show a linear behavior, where a $\mathrm{DP}_{\mathrm{v}}$ value correlates to a single tensile index value. In the linear portion of the curve, the tensile index decrease is mainly governed by the loss of $\mathrm{DP}_{\mathrm{v}}$. To the best of our knowledge, this is the first reported linear correlation between the $\mathrm{DP}_{\mathrm{v}}$ and the tensile index within a range of $150-190{ }^{\circ} \mathrm{C}$.

Figure 4 shows the changes in methanol concentration with the average number of scissions (NS). The average number of scissions of the cellulose chain is defined as $\left(\mathrm{DP}_{\mathrm{v}, \mathrm{o}} / \mathrm{DP}_{\mathrm{v}, \mathrm{t}}\right)-1$, where $\mathrm{DP}_{\mathrm{v}, \mathrm{o}}$ and $\mathrm{DP}_{\mathrm{v}, \mathrm{t}}$ are respectively the initial degree of polymerization and the degree of polymerization at a specific ageing time. This figure depicts two linear correlations, one for the standard Kraft paper and the other for the TUK paper, independent of temperature. Every new scission in the chain of cellulose produces an increment of methanol at a constant rate. The higher value of methanol concentration for the TUK samples is explained by the higher TUK grammage and the effect of the partition phenomenon.

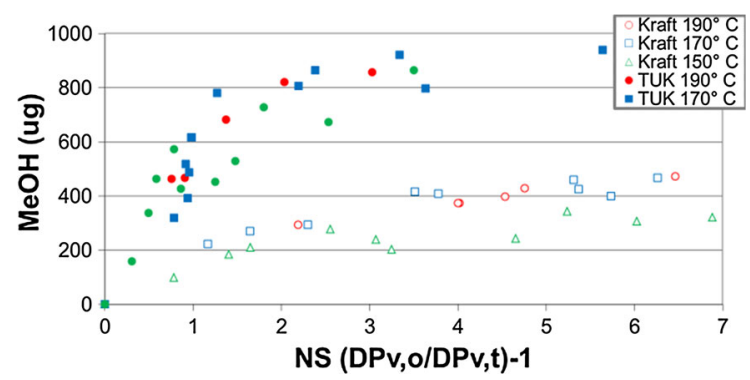

Fig. 4 Correlation between methanol concentration and number of scissions for Kraft and TUK papers at different temperatures
It was observed that NS values higher than seven, $\mathrm{NS} \approx 7$, approximately mark the LODP. However, these scissions are not all necessarily related to the 1 , $4-\beta$-glycosidic bond scissions by acid hydrolysis. The NS increment to values higher than seven is related to the scissions of the cellulose chains by other ageing mechanisms such as the pyrolysis-like mechanism that degrades crystalline cellulose structures.

This correlation is the second linear correlation between methanol and NS that was expanded to a large range of temperatures. Based on the previous correlations, a third correlation was derived between methanol and tensile index.

Figure 5 shows a linear correlation between the tensile index and the methanol concentration at different temperatures. Two linear sections of this correlation were observed, one for standard Kraft and one for TUK. The partition phenomenon of methanol as previously mentioned could explain the different concentrations of methanol.

The importance of this third correlation relates to the information provided by the methanol as a chemical marker for the actual state of the cellulose chains at the molecular level with the actual mechanical strength of the paper at a macro-structural level through the tensile index. This correlation implies that increments in the concentration of methanol in oil are related to a decrease in the tensile index and finally a reduction in the paper strength.

The validity of the correlation was extended from 150 to $190{ }^{\circ} \mathrm{C}$. Therefore, it can be inferred that this correlation could also be valid at lower temperatures close to those of in-service power transformers. However, this correlation cannot be directly applied to the assessment of power transformers because neither laboratory conditions nor the ageing cells used

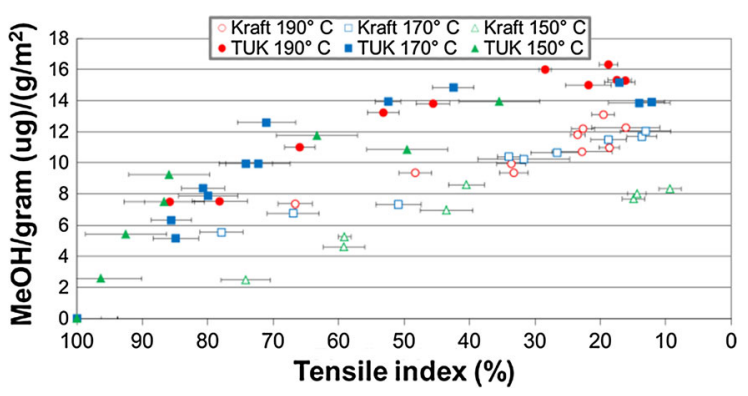

Fig. 5 Correlation between the tensile index and methanol concentration in Luminol 
in this study are exactly the same as a power transformer. Another drawback is the variability of the tensile index results. Nevertheless, this correlation has tremendous potential as a tool for assessing the actual state of the solid insulation of power transformers.

Kinetics of the mechanical properties of paper changes during high temperature ageing-Modeling the change or degradation of the mechanical properties of paper is a complex task. The different structural levels of paper (Kortschot 1997) start at a molecular level, including cellulose molecular weight and degree of polymerization. The depolymerization of cellulose paper is directly related to the loss of its mechanical strength. At a microstructural level, the paper contains micro fibrils, fibrils, fibres, cracks and pores. The strength of individual cellulose fibrils/fibres together with the bond strength among the cellulose fibres assures the strength of paper at this level. At a macrostructural level, the parameters involved in the mechanical strength of paper are the distribution of the mass or density, fibre orientation, impurities and manufacturing defects that create specific points where the mechanical properties of the paper are lower in comparison with the average value. However, as previously mentioned, the change or loss of the mechanical properties of paper starts at the molecular level with cellulose depolymerization.

The relationships among depolymerization, the generation of methanol and the decrease of mechanical strength of the paper were found to be direct and linear over the studied temperature range. Based on these findings and the close physical connection, cellulose depolymerization generates methanol with a concomitant decrease of the mechanical properties. Thus the kinetics of these reactions should show similarities.

The kinetics of cellulose depolymerization has been studied using different equations to model the change of the rate of scissions over time. In a recent study, depolymerization was modeled using a modified two first-order Calvini's kinetics equation (Calvini et al. 2007; Jalbert et al. 2015). This model takes into account the amorphous and crystalline regions in separate terms. Using this model, (Jalbert et al. 2015) reached a good regression for accelerated ageing results. In the same study, based on the linear correlation between depolymerization and generation of methanol, the model was also applied to the generation of methanol with good regression results. In both cases, the Arrhenius equation was used to calculate the activation energy of the depolymerization reaction and for the generation of methanol.

The modified Calvini's Eq. (1) (Calvini et al. 2007; Jalbert et al. 2015) applied to tensile index was proposed for modeling the kinetics of the changes in the mechanical properties of the paper.

$$
\left[\frac{T i d x_{0}}{T i d x_{t}}-1\right]=n_{a}^{0}\left(1-e^{-k_{a} t}\right)+n_{c}^{0} k_{c} t
$$

where $\operatorname{Tidx}_{0}$ is the initial tensile index and $\operatorname{Tidx}_{\mathrm{t}}$ is the tensile index at a specific time. $\mathrm{n}_{\mathrm{a}}^{0}$ and $\mathrm{n}_{\mathrm{c}}^{0}$ are the initial amount of glycosidic bonds in the amorphous and crystalline regions respectively; $\mathrm{k}_{\mathrm{a}}$ and $\mathrm{k}_{\mathrm{c}}$ are reaction rate constants for the amorphous and crystalline regions, while $t$ is the ageing time.

Equation (1) provides the parameters $\mathrm{k}_{\mathrm{a}}$ and $\mathrm{n}_{\mathrm{c}}^{0} \mathrm{k}_{\mathrm{c}}$ needed to calculate the activation energy for the reaction $\left(E_{a}\right)$ from the Arrhenius Eq. (2) by using the slope of the plot, $\ln \mathrm{k}$ versus $1 / \mathrm{T}$ and the frequency factor (ln Aa) (Fig. 6). An Arrhenius model should only be used when a single mechanism drives the phenomena (Zou et al. 1996a, b). The acid hydrolysis was recognized as the main ageing mechanism that reduces the mechanical properties of paper resulting in embrittlement (Arroyo et al. 2015; Gurnagul et al. 1993). Therefore, the use of the Arrhenius equation as a reaction model was acceptable. The experimental results were modelled using the Origin 9 software to calculate the values of all the parameters.

The dependence of $\ln \mathrm{k}_{\mathrm{a}}$ versus 1/T (Fig. 6) depicts a linear relationship between these parameters, for both types of paper. The significant calculated variation of $\mathrm{k}_{\mathrm{a}}$ for the kinetics of change of the mechanical properties of paper can be related to the higher

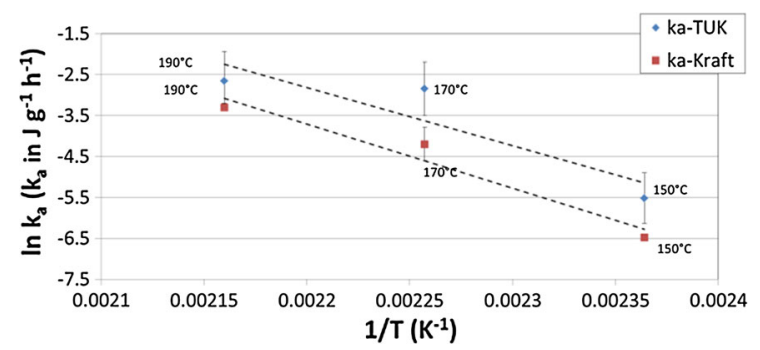

Fig. 6 Arrhenius equation of the $\mathrm{k}_{\mathrm{a}}$ for Kraft and TUK papers over $150-190{ }^{\circ} \mathrm{C}$ for the change in the mechanical properties of paper 
variation observed in the measurement of tensile index. The measurements of $\mathrm{DP}_{\mathrm{v}}$ and methanol concentration show lower variations.

The results confirm the concept that a single reaction mainly rules the ageing of cellulose and therefore the reduction of tensile index over time.

$\ln (k)=\frac{-E_{a}}{R} \frac{1}{T}+\ln \left(A_{a}\right)$

where $\mathrm{k}$ takes the values of $\mathrm{k}_{\mathrm{a}}$ and $\mathrm{k}_{\mathrm{c}} \mathrm{n}_{\mathrm{c}}^{0}$ and $\mathrm{R}$ is the ideal gas constant. The values of $E_{a}$ are reported in Table 1.

In order to assure the applicability of this model, the kinetic Eq. (1) was also used to calculate the activation energy for depolymerization and methanol generation using the accelerated ageing results (Table 1). The results were compared to values previously reported in the literature.

The comparison of the activation energy for cellulose depolymerization with previous studies confirmed that the resulting values are similar and have the same magnitude range. In this work, the depolymerization activation energy $\left(E_{a}\right)$ was determined at $113 \pm$ $17 \mathrm{~kJ} / \mathrm{mol}$ for Kraft and $179 \pm 5 \mathrm{~kJ} / \mathrm{mol}$ for TUK. Emsley and Stevens (1994) obtained $111 \pm 6 \mathrm{~kJ} / \mathrm{mol}$ for Kraft; Lundgaard et al. (2004) $114 \mathrm{~kJ} / \mathrm{mol}$ and $110 \mathrm{~kJ} / \mathrm{mol}$ for Kraft and upgraded paper samples while Jalbert et al. (2015) $116 \pm 8 \mathrm{~kJ} / \mathrm{mol}$ for Kraft and $148 \pm 14 \mathrm{~kJ} / \mathrm{mol}$ for TUK.

Regarding the $\mathrm{E}_{\mathrm{a}}$ of methanol formation for the Kraft and TUK papers, $100 \pm 9 \mathrm{~kJ} / \mathrm{mol}$ and $133 \pm$ $11 \mathrm{~kJ} / \mathrm{mol}$ were respectively reported by Jalbert et al. (Jalbert et al. 2015). In the present study, the results are $95 \pm 31 \mathrm{~kJ} / \mathrm{mol}$ for Kraft and $130 \pm 35 \mathrm{~kJ} / \mathrm{mol}$ for
TUK. Even though an appreciable difference was observed in the determination of the activation energies; the similarity between these values with the ones reported in the literature shows the good fit of the kinetics equation used to describe both reactions.

For the activation energy related to the change in the tensile index, the values obtained, i.e. $130 \pm 29 \mathrm{~kJ} / \mathrm{mol}$ for Kraft and $117 \pm 55 \mathrm{~kJ} / \mathrm{mol}$ for TUK, are similar to those obtained for depolymerization and methanol formation. The results support the hypothesis that these three reactions are intrinsically and physically related. Acid hydrolysis randomly breaks the glycosidic bonds, thus producing depolymerization and methanol generation, while at the same time depolymerization starts a chain of reactions that cause a decrease in the mechanical properties of paper.

The rate of decay of the tensile index changes with the increment of the ageing temperature. Using a form of the Arrhenius equation (Eq. 3), it is possible to obtain the rate of change of the tensile index at any temperature, including that of in-service power transformers. Similarly, the reaction constants for depolymerization and methanol generation can be extrapolated at lower ageing temperatures.

$\ln \left(\frac{K_{a 1}}{K_{a 2}}\right)=\frac{-E_{a}}{R}\left(\frac{1}{T_{2}}-\frac{1}{T_{1}}\right)$

However, even if it is possible to obtain the values of the reaction constants in the temperature range of inservice power transformers, the extrapolated values cannot be directly applied to real units. This is mainly due to the simplifications made in the ageing cell model used in this study and the laboratory conditions.

Table 1 Activation energy and frequency factor for change in tensile index, depolymerization and methanol formation

\begin{tabular}{|c|c|c|c|c|c|c|c|c|c|c|}
\hline \multirow{2}{*}{$\begin{array}{l}\text { Type } \\
\text { of } \\
\text { paper }\end{array}$} & \multirow{2}{*}{$\begin{array}{l}\text { Range of } \mathrm{T} \\
\text { covered by } \\
\text { linear } \\
\text { regression } \\
\left({ }^{\circ} \mathrm{C}\right)\end{array}$} & \multicolumn{3}{|c|}{ Change of tensile index } & \multicolumn{3}{|c|}{ Depolymerization } & \multicolumn{3}{|c|}{ Methanol formation } \\
\hline & & $r^{2}$ & $\begin{array}{l}\text { Activation } \\
\text { energy }(\mathrm{Ea}) \\
\left(\mathrm{kJ} \mathrm{mol}^{-1}\right)\end{array}$ & $\begin{array}{l}\text { Frequency } \\
\text { factor (in } \\
A_{a} \text { ) }\end{array}$ & $\mathrm{r}^{2}$ & $\begin{array}{l}\text { Activation } \\
\text { energy }(\mathrm{Ea}) \\
\left(\mathrm{kJ} \mathrm{mol}^{-1}\right)\end{array}$ & $\begin{array}{l}\text { Frequency } \\
\text { factor (in } \\
A_{a} \text { ) }\end{array}$ & $\mathrm{r}^{2}$ & $\begin{array}{l}\text { Activation } \\
\text { energy }(\mathrm{Ea}) \\
\left(\mathrm{kJ} \mathrm{mol}^{-1}\right)\end{array}$ & $\begin{array}{l}\text { Frequency } \\
\text { factor (in } \\
\mathrm{A}_{\mathrm{a}} \text { ) }\end{array}$ \\
\hline \multicolumn{11}{|l|}{ Kraft } \\
\hline $\mathrm{K}_{\mathrm{a}}$ & $150-190$ & 0.95 & $130.2 \pm 29.1$ & $30.7 \pm 7.9$ & 0.99 & $113.7 \pm 17.5$ & $26.7 \pm 4.7$ & 0.94 & $95.9 \pm 31.6$ & $21.8 \pm 8.6$ \\
\hline $\mathrm{n}_{\mathrm{c}}^{0} \mathrm{k}_{\mathrm{c}}$ & $150-190$ & 0.91 & $101.9 \pm 30.4$ & $22.2 \pm 8.2$ & 0.95 & $124.7 \pm 30.0$ & $28.8 \pm 8.1$ & 0.96 & $126.3 \pm 20.8$ & $28.7 \pm 5.6$ \\
\hline \multicolumn{11}{|l|}{ TUK } \\
\hline $\mathrm{K}_{\mathrm{a}}$ & $150-190$ & 0.82 & $117.9 \pm 55.2$ & $28.3 \pm 15.0$ & 0.96 & $179.8 \pm 5.4$ & $45.7 \pm 14.9$ & 0.96 & $130.3 \pm 35.5$ & $31.0 \pm 9.6$ \\
\hline $\mathrm{n}_{\mathrm{c}}^{0} \mathrm{k}_{\mathrm{c}}$ & $150-190$ & 0.98 & $142.0 \pm 2.5$ & $32.2 \pm 0.7$ & 0.96 & $172.6 \pm 10.5$ & $41.5 \pm 2.8$ & 0.96 & $102.1 \pm 7.5$ & $22.1 \pm 2.0$ \\
\hline
\end{tabular}




\section{Conclusions}

In this study, linear relationships were established between the degree of polymerization, the methanol concentration in oil and the tensile index for different papers aged at different temperatures. The acid hydrolysis was found to be responsible of the main ageing mechanism at the origin of the paper mechanical properties with concomitant embrittlement. In addition, it was shown that the depolymerization of the cellulose, the generation of methanol along with the change of mechanical strength of the paper were adequately modeled using Calvini's modified equation. The influence of the ageing temperature on these processes was observed and modeled using the Arrhenius model with satisfactory results. These processes depict an exponential behaviour during the ageing processes.

The activation energies of the three studied reactions are similar in magnitude, which supports the hypothesis that these three ageing parameters are closely and physically related.

The results show that it is possible to indirectly obtain information on the actual mechanical state of the paper using methanol as a chemical marker. Methanol proves to be effective as a good ageing marker that follows the ageing steps for standard and thermally upgraded Kraft paper.

The ageing behaviour is the same for Kraft and TUK paper since both papers are based on cellulose. The main difference consists in a slowing ageing process for TUK paper due to the addition of nitrogenous-based compounds that partially neutralize the attack of the acids against the cellulose and react in contact with water. The addition of these bases increases the required time to reach LODP in comparison with a regular Kraft paper. However, similar degradation steps should be observed for the ageing process in both types of paper but with a different time frame. The addition of nitrogen additives also affects the methanol concentration in the oil.

These results have the potential to be used as a basis for the development of practical monitoring tools for assessing the condition of operating power transformers during the different ageing stages. The results presented can be seen as a benchmark and a challenge for further research in this field. More studies are needed by considering additional parameters or conditions to improve the simplified model presented in this study.

Acknowledgments The authors would like to thank HydroQuébec, Electricité de France and MITACS for supporting this project. They would also like to thank Steve Duchesne, MarieJosée Vigeant, Sylvie Gagnon, Kim Noël and Brigitte Morin from IREQ for their technical assistance.

Open Access This article is distributed under the terms of the Creative Commons Attribution 4.0 International License (http:// creativecommons.org/licenses/by/4.0/), which permits unrestricted use, distribution, and reproduction in any medium, provided you give appropriate credit to the original author(s) and the source, provide a link to the Creative Commons license, and indicate if changes were made.

\section{References}

Arroyo OH, Fofana I, Jalbert J (2014) Relationship between some chemical markers and the mechanical properties of the solid insulation used in power transformers. In: 2014 IEEE Electrical Insulation Conference (EIC). Doi: 10. 1109/EIC.2014.6869407

Arroyo OH, Fofana I, Jalbert J, Ryadi M (2015) Relationships between methanol marker and mechanical performance of electrical insulation papers for power transformers under accelerated thermal aging. IEEE Trans Dielectr Electr Insul 22(6):3625-3632. doi:10.1109/TDEI.2015.005386

Calvini Paolo, Gorassini Andrea, Merlani Antonio Luigi (2007) On the kinetics of cellulose degradation: looking beyond the pseudo zero order rate equation. Cellulose 15(2):193-203. doi:10.1007/s 10570-007-9162-8

Emsley AM, Stevens GC (1994) Kinetics and mechanisms of the low-temperature degradation of cellulose. Cellulose 1(1):26-56. doi:10.1007/bf00818797

Gilbert R, Jalbert J, Tétreault P, Morin B, Denos Y (2009) Kinetics of the production of chain-end groups and methanol from the depolymerization of cellulose during the ageing of paper/oil systems. Part 1: standard wood kraft insulation. Cellulose 16(2):327-338. doi:10.1007/s10570008-9261-1

Gilbert Roland, Jalbert Jocelyn, Duchesne Steve, Tétreault Pierre, Morin Brigitte, Denos Yves (2010) Kinetics of the production of chain-end groups and methanol from the depolymerization of cellulose during the ageing of paper/ oil systems. Part 2: thermally-upgraded insulating papers. Cellulose 17(2):253-269. doi:10.1007/s10570-009-9365-2

Gurnagul Norayr, Howard RC, Zou Xuejun, Uesaka Tetsu, Page DH (1993) The mechanical permanence of paper: a literature review. J Pulp Pap Sci 19:J160-J160

Jalbert J, Gilbert R, Tétreault P, Morin B, Lessard-Déziel D (2007) Identification of a chemical indicator of the rupture of 1,4- $\beta$-glycosidic bonds of cellulose in an oil-impregnated insulating paper system. Cellulose 14(4):295-309. doi:10.1007/s10570-007-9124-1 
Jalbert J, Duchesne S, Rodriguez-Celis E, Tétreault P, Collin P (2012) Robust and sensitive analysis of methanol and ethanol from cellulose degradation in mineral oils. J Chromatogr A 1256:240-245. doi:10.1016/j.chroma. 2012.07.069

Jalbert J, Lessard MC, Ryadi M (2013) Cellulose chemical markers in transformer oil insulation Part 1: temperature correction factors. IEEE Trans Dielectr Electr Insul 20(6):2287-2291. doi:10.1109/TDEI.2013.6678881

Jalbert J, Rodriguez-Celis E, Duchesne S, Morin B, Ryadi M, Gilbert R (2015) Kinetics of the production of chain-end groups and methanol from the depolymerization of cellulose during the ageing of paper/oil systems. Part 3: extension of the study under temperature conditions over $120{ }^{\circ} \mathrm{C}$. Cellulose 22(1):829-848. doi:10.1007/s10570014-0516-8

Kortschot MT (1997) The role of the fibre in the structural hierarchy of paper. In: The fundamentals of papermaking materials, the eleventh fundamental research symposium (21-26 September 1997)

Lessard MC, Lamarre C, Gendron A, Massé M (1995) Determination of paper degradation by-products by direct injection on an HPLC column. In: Electrical insulation and dielectric phenomena, 1995. annual report. Conference on. Doi: 10.1109/CEIDP.1995.483705
Lundgaard LE, Hansen W, Linhjell D, Painter TJ (2004) Aging of oil-impregnated paper in power transformers. IEEE Trans Power Delivery 19(1):230-239. doi:10.1109/ TPWRD.2003.820175

Rodriguez-Celis EM, Duchesne S, Jalbert J, Ryadi M (2015) Understanding ethanol versus methanol formation from insulating paper in power transformers. Cellulose 22(5):3225-3236. doi:10.1007/s10570-015-0693-0

Wang M, Vandermaar AJ, Srivastava KD (2002) Review of condition assessment of power transformers in service. IEEE Electr Insul Mag 18(6):12-25. doi:10.1109/MEI. 2002.1161455

Yamagata N, Katsunori M, Etsuo O (2008) Diagnosis of thermal degradation for thermally upgraded paper in mineral oil. Condition monitoring and diagnosis, 2008. CMD 2008. In: International conference on. Doi:10.1109/CMD.2008. 4580450

Zou X, Uesaka T, Gurnagul N (1996a) Prediction of paper permanence by accelerated aging I. Kinetic analysis of the aging process. Cellulose 3(1):243-267. doi:10.1007/ bf02228805

Zou X, Uesaka T, Gurnagul N (1996b) Prediction of paper permanence by accelerated aging II. Comparison of the predictions with natural aging results. Cellulose 3(1):269-279. doi:10.1007/bf02228806 